\title{
Absorption of Sterols and Cholesteryl Esters in a Prawn, Penaeus japonicus
}

\author{
Shin-ichi Teshima, ${ }^{* 1}$ Akio Kanazawa, ${ }^{* 1}$ and Haruhito OKamoto ${ }^{* 1}$ \\ (Received May 27, 1974)
}

\begin{abstract}
This study deals with the absorption of sterols and cholesteryl esters in a prawn,Penaeus japonics. The apparent percentage absorption of these substances was estimated by an indirect method using chromium oxide as an indicator. The sterols and cholesteryl esters examined gave percentage absorptions of $60.8-98.8 \%$ and $67.0-87.3 \%$, respectively. The cholesterol level in the diet affected somewhat the percentage absorption of cholesterol in this prawn. The prawns fed on the $0.05-1.0 \%$ levels of cholesterol showed similar percentage absorptions whereas the high doses $(2.0 \%$ and $5.0 \%)$ of diet cholesterol caused a decrease in the percentage absorption of cholesterol.
\end{abstract}

A prawn, Penaeus japonicus, has begun to arouse considerable attention in the field of aquaculture due to economically high value and demand in Japan. Kanazawa et al." have devised the synthetic diet composed of chemically known substances for nutritional study in the prawn, $P$. japonicus. Also, SHIGeno et al. ${ }^{2)}$ have studied the relationship between the feed efficiency and crude protein content in a diet, using the several artificial diets composed of mainly cuttlefish meal, white fish meal, dry powder of mysid shrimp, active sludge, yeast etc. However, the nutritional requirements of this crustacean are not understood so fully yet.

On the other hand, the crustaceans have the stiff exoskeletons and grow by repeating exuviation, and the metabolism of them has been pointed out to be unique in some points. For example, the authors ${ }^{3}$ have demonstrated that the prawn, P. japonicus, is incapable of synthesizing sterols from acetate, although higher animals generally possess the ability for sterol synthesis from lower units. Moreover, Kanazawa et al. ${ }^{4)}$ have shown by the nutritional experiments that the prawn, $P$. japonicus, requires cholesterol and other sterols as essential nutrients for normal growth. Their results have supported the absence of sterol synthesis in this crustacean, and also suggested that most crustaceans lacking sterolsynthesizing ability may require a dietary source of sterols.

As mentioned above, sterols appear to be undoubtedly essential substances for the growth of prawns and other crustaceans. However, the knowledge of sterol metabolism in crustaceans is only a little. As a part of nutritional study on the prawn, $P$. japonicus, hence, the authors intended to investigate the intestinal absorption of sterols. This paper deals with the absorption rate of sterols and cholesteryl esters, and with the effect of cholesterol levels in the diet on the absorption of cholesterol from the intestines in the prawn.

\footnotetext{
${ }^{* 1}$ Faculty of Fisheries, University of Kagoshima, 4-50-20 Shimoarata, Kagoshima City (手島新一・ 金沢昭夫・周本春人：鹿児島大学水産学部)
} 


\section{Materials and Methods}

Prawn and culture method The prawns, $P$, japonicus, about $5 \mathrm{~g}$ in average body weight, were cultivated in a cirulating aquarium at $23-25^{\circ} \mathrm{C}$. The prawns were maintained on the synthetic diet devised by KANAZAWA et al. ${ }^{11}$ for 2 weeks, and then fasted for 2 days prior to the adminstration of test diets. The prawns were put into 14 groups (each group; 15 prawns) and given the test diets. The test diets were prepared as follows: To the basal synthetic diet (sterol-free) containing $0.5 \%$ of chromium oxide as an indicator, $0.5 \%$ each of cholesterol, 7-cholestenol, ergosterol, 24-methylenecholesterol, brassicasterol, stigmasterol, fucosterol, $\beta$-sitosterol, cholesteryl acetate, cholesteryl laurate, cholesteryl myristate, cholesteryl palmitate, cholesteryl oleate, and cholesteryl linolenate was added separately. The sterols and cholesteryl esters were suspended in a soy-bean oil and added to the basal diet. The details of the methods for preparation of the diets were essentially the same as repoted by KanAZAWA et al. ${ }^{21}$

In the second experiment, the effect of cholesterol levels in the diet on the absorption of cholesterol from the intestines was examined by using the 6 diets containing $0.05 \%$, $0.1 \%, 0.5 \%, 1.0 \%, 2.0 \%$ and $5.0 \%$ of levels of cholesterol.

Measurement of absorption rate The prawns were given the test diets after sunset, and the feces were collected in the early morning of next day. The 6 day-pools of feces were subjected to the determination of sterol and chromium oxide concetrations. The feces were dried in an oven at $70-75^{\circ} \mathrm{C}$ for 60 minutes, and then refluxed twice with chloroformmethanol (2: 1). The residues were used for the determination of chromium oxide concentration by the method of DANSKY and HrLL. ${ }^{5 /}$ The lipids were saponified with alcoholic potassium hydroxide, and the unsaponifiable matters were obtained from the saponification mixtures by extraction with ether in the usual manner. The unsaponifiable matters were subjected to gas-liquid chromatography (CLC) on $\left.1.5 \% \mathrm{OV}-17^{8}\right)$ in order to determine the sterol concentration. In GLC, the sterol concentration was quantitatively determined by using cholestane as an internal standard.

The apparent absorption rate of sterols and cholesteryl esters is given as follows: apparent absorption rate $(\%)=(1-c / a \times b / d) 100$

a: Sterol $(\%)$ of dry diet

b: Chromium oxide (\%) of dry diet

c: Sterol $(\%)$ of dry feces

d: Chromium oxide $(\%)$ of dry feces

\section{Results and Discussion}

Table 1 shows the percentage absorption of sterols and cholesteryl esters in the prawn, $P$. japonicus. In this study, the percentage absorption of sterols and cholesteryl esters 
Table 1. The percentage absorption of sterols and cholesteryl esters from the digestive tracts in the prawn, $P$. japonicus

\begin{tabular}{lc}
\hline Substance & Absorption (\%) \\
\hline Cholesterol & 82.6 \\
7-Cholestenol & 63.0 \\
Ergosterol & 96.6 \\
24-Methylenecholesterol & 92.3 \\
Brassicasterol & 77.3 \\
Stigmasterol & 60.8 \\
Fucosterol & 94.6 \\
B-Sitosterol & 98.8 \\
Cholesteryl acetate & 85.2 \\
Cholesteryl laurate & 67.0 \\
Cholesteryl myristate & 81.3 \\
Cholesteryl palmitate & 78.3 \\
Cholesteryl oleate & 77.2 \\
Cholesteryl linolenate & 87.3 \\
\hline
\end{tabular}

was estimated by an indirect method using chromium oxide as an indicator. This method has been widely used for measurement of digestibility for dietary nutrients in mammals and fish, but involves the error due to endogenously formed ones. Accordingly, the value estimated in the present study should be regarded as apparent percentage absorption from the digestive tracts.

The free sterols examined gave the apparent percentage absorption of 60.8-98.8. Cholesterol, ergosterol, 24-methylenecholesterol, brassicasterol, fucosterol, and $\beta$-sitosterol showed considerably high percentage absorptions, whereas 7-cholestenol and stigmasterol seemed to be less absorbed than the above 6 sterols. The cholesteryl esters revealed the percentage absorption of 67.0-87.3; cholesteryl linolenate and cholesteryl laurate gave the highest and lowest values, respectively. Cholesteryl acetate, cholesteryl myristate, cholesteryl palmitate, and cholesteryl oleate demonstrated the almost same value each other, and these 4 cholesteryl esters also showed the percentage absorptions close to that of cholesterol.

BORGSTRÖM $^{\text {7) }}$ has studied the quantitative aspects of the intestinal absorption and metabolism of cholesterol and $\beta$-sitosterol in the rats, and reported that $\beta$-sitosterol was absorbed in amounts only one-tenth of the corresponding dose of cholesterol. He has suggested that the difference in the absorption between the above 2 sterols was based on the discrepancy during the process of uptake into the intestinal mucosa. Compared with the rats, the prawn, P. japonicus, was found to absorb highly sterols other than cholesterol. KANAZAWA et $\left.a l^{4}\right)$ have demonstrated by the feeding experiments that the prawn, $P$. japonicus, is capable of utilizing ergosterol, stigmasterol, and $\beta$-sitosterol to some extend as a substituent of cholesterol for normal growth. In conjunction with the possible bioconversions of these sterols to cholesterol $^{8}$, the considerably high percentage absorption 
of these sterols in the digestive tracts of this prawn supports their results showing the utilization of $\mathrm{C}_{28^{-}}$and $\mathrm{C}_{29^{-}}$-sterols for growth.

In marine crustaceans, there are little informations about the digestibility and absorption of dietary lipids. In vertebrates, the main surfactants are generally recognized to be bile salts which are derived from cholesterol. In earlier studies, a crab, Cancer pagurus, and a crayfish, Astacus astacus, were conceived to contain tauro-deoxycholic acid in the gastric juices., ${ }^{90}$ Later on, VoNk has pointed out that some crustaceans and other invertebrates contain the surface active compounds differing from bile salts in their gastric juices. ${ }^{11)}$ Also, VAN DEN OORD et al. ${ }^{12)}$ have shown by using chromatographic and mass spectrometric methods that the crab, C. pagurus, lacks bile salts in the gastric juices and is incapable of synthesizing bile salts from cholesterol-4 ${ }^{14} \mathrm{C}$, although this animal contains cholesterol in the tissues. Furthermore, it has been reported that the emulsifiers purified from the gastric juice of the crab, $C$. pagurus, are fatty acylsarcosyltaurines ${ }^{13)}$ and are of endogenous origin. ${ }^{14}$ Considering these facts, it may be assumed that the lipid metabolism in crustaceans, especially on the digestion and absorption, is considerably different with that in vertebrates, and also that the lack of pathways from cholesterol to bile salts is probably correlated with the unique aspect of sterol metabolism in crustaceans.

Table 2 shows the percentage absorption of cholesterol in the prawn, P. japonicus, fed on the diets containing different levels of cholesterol. The cholesterol levels in the diet fairly affected on the percentage absorption of cholesterol in the prawn. The prawns fed on the $0.05-1.0 \%$ levels of cholesterol showed the almost similar absorption of cholesterol each other. But, the high dose $(2.0 \%$ znd $5.0 \%)$ of cholesterol to the diet caused the decrease in absorption of cholesterol from the digestive tracts. KANAzAwA et al. ${ }^{4 \prime}$ have reported that the administration of $0.5-1.0 \%$ levels of cholesterol gave the maximum growth and survival rate of the prawn, $P$. japonicus, in the feeding trials using the synthetic diet. Quite recently, Deshimaru and coworker ${ }^{15)}$ have prepared another type of the synthetic diet for nutritional study of the prawn, $P$. japonicus, and then demonstrated that the best growth of this was attained by the diet containing $2.1 \%$ level of cholesterol. ${ }^{16}$ ) In mammals, total body cholesterol is regulated mainly by the interaction of absorption,

Table 2. Effect of the cholesterol levels in the diet on the percentage absorption of cholesterol

\begin{tabular}{|c|c|c|}
\hline & $\begin{array}{c}\text { Cholesterol levels in the diet } \\
(\%)\end{array}$ & $\%$ Absorption of cholesterol \\
\hline & 0.05 & 87.1 \\
\hline & 0.1 & 82.6 \\
\hline & 0.5 & 83.6 \\
\hline & 1.0 & 81.4 \\
\hline & 2.0 & 71.3 \\
\hline & 5.0 & 58.3 \\
\hline
\end{tabular}


synthesis, excretion, and bioconversion to bile salts. Since the prawn, $P$. japonicus, lacks the sterol-synthesizing ability and probably bile salts, the regulatory mechanism of total body cholesterol is assumed to be greatly different with that in mammals. However, there is no report about the regulation of cholesterol metabolism, including absorption, in the prawn, $P$. japonicus. Accordingly, the relationship between the absorption of cholesterol and the composition of diets was not discussed in the present study, although the authors postulate that the composition of diets highly affects on the percentage absorption of cholesterol from the discrepancy in cholesterol levels giving the best growth between the nutritional investigations of KanazaWa et al. ${ }^{4)}$ and Deshimaru and coworker. ${ }^{16 \text { ? }}$

\section{Acknowledgements}

This work was supported financially by the funds from both the Japan Society of the Promotion of Science and the Ministry of Education of Japan.

\section{References}

1) A. Kanazawa, M. Shimaya, M. Kawasaki and K. Kashiwada: This Bull., 36, 949-954 (1970).

2) K. Shugeno, K. Kumanda, O. Deshimaru, T. Aramaki, K. Kuroki and K. Kitaue: ibid., 38, 101106 (1972).

3) S. Teshima and A. Kanazawa: Comp. Biochem. Physiol., 38B, 597-602 (1971).

4) A. Kanazawa, N. Tanaka, S. Teshima and K. Kashiwada: This Bull,, 37 211-125 (1971).

5) L. M. DANSKY and F. W. Hill: J. Nutrition, 47, 449-459 (1952).

6) S. Teshima, A. Kanazawa and T. Ando: Mem. Fac. Fish., Kagoshima Univ., 20, 131-139 (1971).

7) B. Borgström: J. Lipid Res., 9, 473-481 (1968).

8) S. Teshima: Mem. Fac. Fish., Kagoshima Univ., 21, 69-147 (1972).

9) H. J. Vonk: Bull. Soc. Chim. Biol., 29, 94-96 (1947).

10) H. J. Vonk: In "The Physiology of Crustacea" (ed. by T. H. Waterman), Vol. 1, Academic Press, New York, 1960, pp. 291-316.

11) H. J. Vonk: Arch. Int. Physiol. Biochim., 70, 67-85 (1962).

12) A. Van den Oors, H. Danielsson and R. Ryhage: Nature, 203, 301-302 (1964).

13) A. VAN DEN OORD, H. DANIELSSON and R. RYHAGE: J. Biol. Chem., 240, 2242-2247 (1965).

14) A. VAN Den Oord: Comp. Biochem. Fhysiol., 17, 715-718 (1966).

15) O. Deshimaru and K. Kuroki: This Bull., 40, 413-419 (1974).

16) O. Deshrmaru and K. KuRoKI: ibid., 40, 421-424 (1974). 